\title{
БЛАГОСОСТОЯНИЕ НАСЕЛЕНИЯ КАК ФАКТОР РАЗВИТИЯ СТРАХОВОГО РЫНКА
}

\begin{abstract}
АннотАция. Развитие страхового рынка напрямую связано с уровнем благосостояния населения и субъектов предпринимательской деятельности, поскольку страхование как таковое возникает в результате перераспределения доходов физических и юридических лиц. На формирование спроса на страховые услуги оказывают влияние потребность в возмещении ущербов, информированность потенциальных страхователей о сущности и видах страхования и наличие денежных ресурсов, которые можно направить на страхование. О последних можно сказать, что это свободные денежные средства. Страхование является способом защиты и одним из методов управления рисками (передача риска), поэтому, с нашей точки зрения, затраты на страхование должны включаться в перечень необходимых семейных расходов или расходов предпринимателя. В настоящей статье на основе статистических данных рассматривается благосостояние населения как фактор развития страхования, в значении именно материальной составляющей, путем сопоставления доходов населения, структуры расходов населения, доли доходов, направляемых на сбережения и показателей среднего страхового взноса по договорам страхования.

кЛЮчЕВЫЕ СЛОВА. Страховой рынок; доходы населения; расходы населения на страхование; факторы развития страхового рынка; проблемы развития страхования; сбережения населения; средний страховой взнос; основные показатели страховой деятельности, страховая культура.

ИНФОРМАЦИЯ О СТАТЬЕ. Дата поступления 12 октября 2016 г.; дата принятия к печати 24 октября 2016 г.; дата онлайн-размещения 30 ноября 2016 г.
\end{abstract}

\section{N. V. Kuznetsova Baikal State University, Irkutsk, Russian Federation}

\section{HUMAN WELFARE AS A FACTOR OF INSURANCE MARKET DEVELOPMENT}

\begin{abstract}
Development of the insurance market is directly connected with human welfare level and business entities, because insurance, as it is, results from redistributing incomes of individuals and legal entities. Generating demand for insurance services is influenced by the need for reparation of damages, information awareness of potential insurers about the essence and types of insurance and availability of money resources which can be directed to insurance. One can say about the latter that these are free monetary funds. Insurance is a way of protection and one of the methods of risk management (transfer of risk), so, from our point of view, insurance costs should be included in the list of necessary family expenses or businessman's costs. On the basis of statistical data, the article considers human wellbeing as a factor of insurance development, in the meaning of exactly material component, by way of comparing personal incomes, structures of private consumption, shares of income directed at savings and indicators of the average insurance fee in terms of the insurance contract.
\end{abstract}

KEYWORDS. Insurance market; personal incomes; public expenditures on insurance; factors of insurance market development; problems of insurance development;

(C) Н. В. Кузнещова, 2016

\section{Baikal Research Journal}


personal savings; average insurance fee; basic indicators of insurance activity; insurance culture.

ARTICLE INFO. Received October 12, 2016; accepted October 23, 2016; available online November 30, 2016.

Под развитием страхового рынка понимается постоянный и непрерывный процесс расширения, углубления и усиление его всестороннего влияния и проникновения в самые разнообразные сферы и области бизнеса [1].

Основными определяющими факторами развития спроса на страховую услугу являются наличие потребности в страховой защите, выражающейся в страховании как элементе риск-менеджмента, а также «растущей покупательной способностью страхователей, позволяющей удовлетворить определенный спрос на страхование приобретением конкретной страховой услуги» ${ }^{1}$.

К важнейшим факторам развития страхового рынка, по мнению профессионалов рынка, относятся: «...интерес инвесторов к учреждению страховых компаний, наличие необходимой статистической и информационной базы для верного расчета страховых тарифов, присутствие возможностей для адекватной оценки страхового риска, достаточно эффективное функционирование финансового рынка, позволяющего гарантировать возврат и прибыльность инвестиций страховых компаний, а также наличие профессиональных менеджеров страховых компаний и специалистов в области андеррайтинга предлагаемых страховых услуг, управления застрахованными рисками и урегулирования претензий [1].

Все эти факторы касаются, прежде всего, страховщиков и государства. Вместе с тем, есть еще многие другие факторы, которые призваны обеспечивать существование страховой отрасли, в числе которых рассматриваются факторы обратной стороны - потребителей страховых услуг - страхователей. В их числе выделим уровень развития страховой культуры и уровень благосостояния населения. Под страховой культурой в данном случае мы понимаем осознание потребителями роли и значения страхования как способа защиты, а также степени информированности страхователей о:

- предлагаемых страховщиками страховых продуктов и программах страхования;

- стоимости страховых услуг;

- возможностях страхования в части накоплений (страхование жизни);

- возможности полной или частичной оплаты услуг (программы добровольного медицинского страхования);

- льгот по налогообложению.

Под материальным благосостоянием понимаем «...такое экономическое положение человека, при котором он в состоянии удовлетворять своим необходимым потребностям» ${ }^{2}$.

Рассмотрение динамики доходов и структуры расходов населения, динамики сбережений, объемов сборов страховых взносов и показателей средней страховой премии по договору страхования, позволит нам представить ситуацию и получить ответы на следующие вопросы: есть ли у населения денежные средства, которые можно направить на страхование (этим определяются потенциальные возможности страхования); как средняя страховая премия по договору страхования соотносится с уровнем доходов населения по годам; как выглядит структура расходов населения и какую долю в них составляют сбережения.

${ }^{1}$ URL: http://www.einsa.ru/news-i56-o-razvitii-strahovogo-rynka.html.

${ }^{2}$ URL: http://dic.academic.ru/dic.nsf/brokgauz_efron.

\section{Baikal Research Journal}


Во внимание принимались общие показатели рынка ${ }^{3}$. Показатель средней страховой премии рассчитывали на основании страховой премии всего по рынку и общего количества договоров страхования. В табл. 1 приведены данные о средней стоимости договора страхования и среднедушевом доходе.

Средняя страховая премия и среднедушевой доход населения

\begin{tabular}{|c|c|c|c|c|c|c|c|c|}
\hline Показатель & 2008 & 2009 & 2010 & 2011 & 2012 & 2013 & 2014 & 2015 \\
\hline $\begin{array}{l}\text { Количество } \\
\text { договоров } \\
\text { страхования, } \\
\text { заключенных } \\
\text { страховщика- } \\
\text { ми, млн } \\
\end{array}$ & 157,8 & 120,0 & 128,1 & 133,2 & 140,7 & 139,1 & 157,9 & 144,7 \\
\hline $\begin{array}{l}\text { Страховые } \\
\text { премии } \\
\text { (взносы), } \\
\text { собранные } \\
\text { страховщика- } \\
\text { ми - всего, } \\
\text { млн р. } \\
\end{array}$ & 954754,2 & 979099,3 & 1036677,0 & 1269762,8 & 811105,2 & 901077,9 & 983400,6 & 1033532,0 \\
\hline $\begin{array}{l}\text { Средняя } \\
\text { страховая } \\
\text { премия, р. } \\
\end{array}$ & 6050,4 & 8159,2 & 8092,7 & 9532,8 & 5764,8 & 6477,9 & 6228,0 & 7142,6 \\
\hline $\begin{array}{l}\text { Среднеду- } \\
\text { шевой доход } \\
\text { населения, p. }\end{array}$ & 14863,6 & 16895,0 & 18958,4 & 20780,0 & 23221,1 & 25928,2 & 27766,6 & 30224,5 \\
\hline
\end{tabular}

Составлено по данным Федеральной службы государственной статистики. URL: http://www.gks.ru.

Период с 2008 по 2015 г. характеризуется кризисами, нашедшими отражение и в динамике показателей. Это 20 \% снижение количества договоров страхования уже в 2009 г. и падение объемов страховых взносов в 2012 г. почти на $40 \%$ по сравнению с 2011 г. К 2015 г. объемы страхового рынка так и не превысили показателя 2011 г. и составили 1 033,5 млрд р., а по прогнозу экспертов рейтингового агентства «Эксперт РА» в 2016 г. «объем рынка не превысит 1070 млрд рублей» ${ }^{2}$

Среднедушевые денежные доходы населения России, по данным Федеральной службы государственной статистики, составили 16895,0 р. в 2009 г., 18958,4 р. в 2010 г., 20780 р. в 2011 г. и 23221,1 р. в 2012 г., 25 928,2 р. в 2013 г., 27 766, 6 р. в 2014 г., 30224,5 р. в 2015 г. Средняя страховая премия в 2008 г. составляла 6050,4 р., к 2011 г. увеличилась почти на 60 \% и составила 9532,8 р., далее снижение до 5764,8 р. В 2015 г. данный показатель составил 7142,6 р. $-118 \%$ от уровня 2008 г. и $75 \%$ от уровня 2011 г. В настоящее время размер средней страховой премии составляет $1 / 4$ часть от среднемесячного дохода или почти $2 \%$ от среднегодового дохода, как и в 2012 г. В 2011 г. эта цифра составляла почти 4 \%.

Наглядно динамика средней страховой премии и среднедушевого дохода населения представлена на рис. 1.

${ }^{3}$ Более подробный сравнительный анализ показателей страховой деятельности, и в частности, размера средней страховой премии может проводиться по добровольным видам страхования: страхованию жизни, страхованию от несчастных случаев и страхованию имущества физических лиц, поскольку развитие именно этих видов страхования, глубже показывает уровень влияния благосостояния населения и влияет на вовлеченность в страхование. В таком случае и показатели доходов и расходов населения необходимо будет коррелировать с учетом расслоения доходов населения, численности населения с доходами ниже величины прожиточного минимума, показателя реально располагаемых доходов населения и т. д.

4 URL: http://www.raexpert.ru/researches/insurance/prognoz_2016/.

\section{Baikal Research Journal}




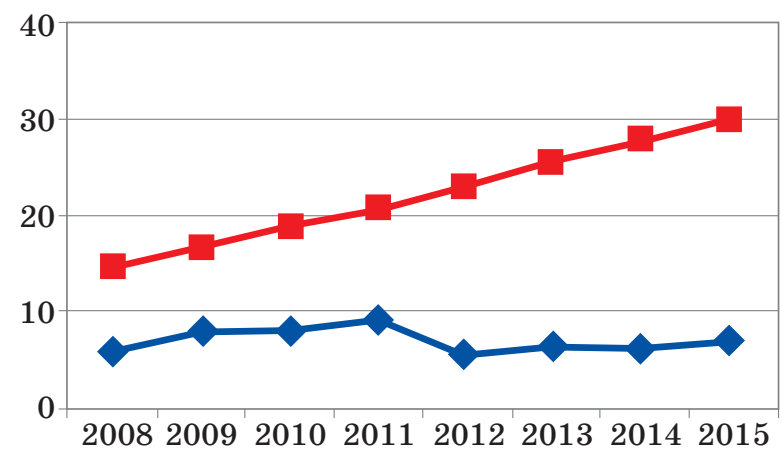

- - Среднедушевой доход населения - Средняя страховая премия

Рис. 1. Диналика показателей средней страховой прелии и среднедушевого дохода населения, тыс. $р$.

(Составлено по даннылм Федеральной службы государственной статистики. URL: http://www.gks.ru)

В табл. 2 и на рис. 2 представлена структура использования денежных доходов населения по группам расходов, в том числе, покупка товаров и приобретение услуг, обязательные платежи и взносы, сбережения.

Таблица 2

Структура использования денежных доходов населения, \%

\begin{tabular}{|c|c|c|c|c|c|c|c|c|}
\hline Денежные доходы & 2008 & 2009 & 2010 & 2011 & 2012 & 2013 & 2014 & 2015 \\
\hline Покупка товаров и оплата услуг & 74,1 & 69,8 & 69,6 & 73,5 & 74,2 & 74,0 & 75,3 & 71,2 \\
\hline Обязательные платежи и взносы & 12,3 & 10,5 & 9,7 & 10,3 & 11,1 & 11,4 & 11,8 & 11,3 \\
\hline Сбережения & 5,3 & 13,9 & 14,8 & 10,4 & 9,9 & 9,9 & 6,9 & 14,1 \\
\hline Покупка валюты & 7,9 & 5,4 & 3,6 & 4,2 & 4,8 & 4,2 & 5,8 & 4,2 \\
\hline $\begin{array}{l}\text { Прирост (уменьшение) денег на } \\
\text { руках у населения }\end{array}$ & 0,4 & 0,4 & 2,3 & 1,6 & - & 0,5 & 0,2 & $-0,8$ \\
\hline Всего & 100,0 & 100,0 & 100,0 & 100,0 & 100,0 & 100,0 & 100,0 & 100,0 \\
\hline
\end{tabular}

Составлено по данным по данным Федеральной службы государственной статистики. URL: http://www.gks.ru.

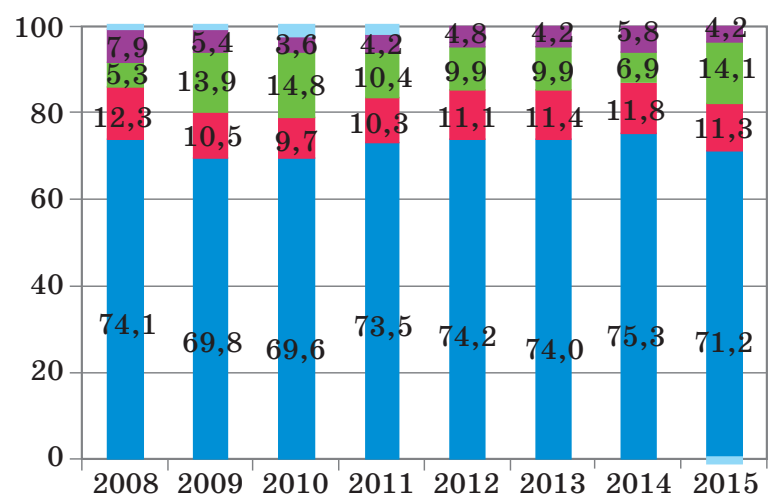

Прирост (уменьшение) денег на руках у населения

口 Обязательные платежи и взносы П Покупка валюты

- Покупка товаров и оплата услуг

Сбережения

Рис. 2. Структура использования денежных доходов населения, \%

(Составлено авторол по данныл по даннылм Федеральной службы государственной статистики. URL: http://www.gks.ru)

\section{Baikal Research Journal}


Статистика показывает, что склонность населения к сбережениям находится на низком уровне (даже при видимом росте доли сбережений в 2015 г.) $-80-85 \%$ расходов приходится на приобретение товаров и услуг и оплату обязательных платежей и взносов. Направлять часть семейного бюджета на страхование для многих семей не представляется возможным [2-4]. По сути, страховые взносы оплачиваются за счет такой статьи расходов как сбережение и, исходя из вышеприведенных нами расчетов о соотношении средней страховой премии и среднедушевого дохода населения, мы видим, что отношение средней страховой премии к «свободным ресурсам населения» составляет: в 2011 г. - почти 20 \%, в 2012 и 2015 гг. - почти 40 \% от сбережений. А с учетом вложения в недвижимость данный показатель уменьшается еще в половину. На рис. 3 наглядно представлена динамика средней страховой премии и сбережений населения в 2008-2015 гг.

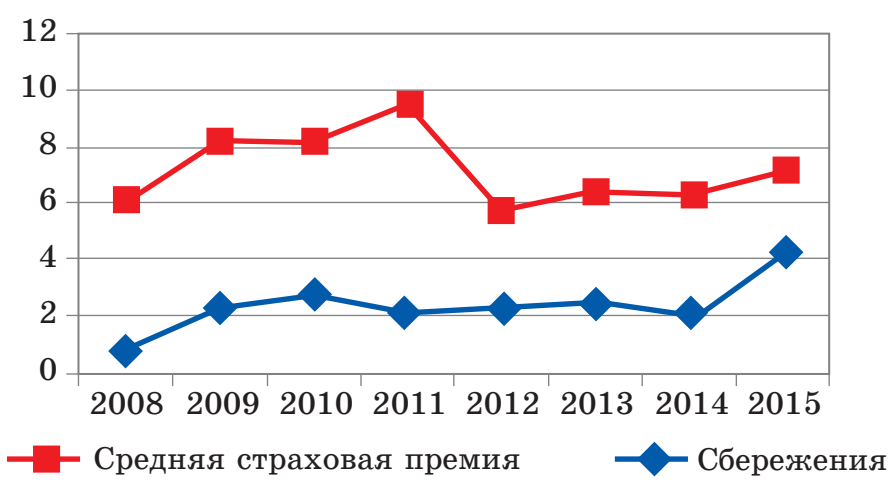

Рис. 3. Динамика средней страховой премии и сбережений населения, тыс. $р$.

(Составлено по данным по данным по данным Федеральной службы государственной статистики. - URL: http://www.gks.ru)

Вопросы влияния благосостояния населения на развитие страхования исследуется во многих научных работах [2; 5-9]. Авторами выделяется понятие «страховая бедность» как фактор сегментации рынка. Обосновывается понятие порог «страховой бедности», где под «страховой бедностью» понимается точка перегиба в зависимости между потребительской оценкой премии, которую определяет склонность к страхованию, и доходами клиента. «Это порог среднедушевого месячного дохода в семье, преодоление которого позволяет отвлекать средства на

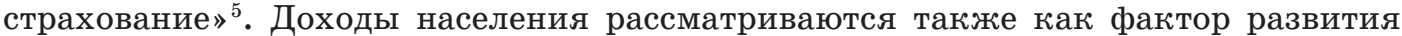
отдельных видов страхования, например, ипотечного, в рамках ипотечного кредитования [10]. На представленных выше графиках прослеживается четкая взаимосвязь доходов населения и объемов страховых премий 6 .

На развитие страхования оказывает огромное влияние само государство. Насколько руководство понимает значение и возможности страхования (а именно функции, которые выполняет страхование: это и покрытие ущерба; и освобождение государства от дополнительных финансовых расходов; и возможность ин-

${ }^{5}$ URL: http://www.vuzllib.su/beta3/html/1/6836/6847/

${ }^{6}$ Развитие страхового рынка, и в частности, сектора страхования физических лиц, конечно же, обуславливается не только уровнем благосостояния населения. Влияет еще и уровень страховой культуры, о чем мы также отмечаем в статье. Кроме того, в страховании важен такой показатель как проникновение страхования или доля застрахованных объектов в общем количестве объектов. По оценкам экспертов в России застраховано от 7 до $12 \%$ всех рисков $[11 ; 12]$, и перспективы для роста объемов страховых платежей в масштабе страны просто огромны. Вместе с тем, вопрос о наличии денежных ресурсов, которые можно направить на страхования и преодоление черты «страховой бедности», как для физических, так и для юридических лиц остается первостепенным.

\section{Baikal Research Journal}


вестирования средств страховых резервов) и какую роль готово сыграть в его развитии, включая вопросы обязательного страхования [12-14]. Здесь важно понимание природы и сущности страхования. Страхование не похоже на нефтяной, на «золотой» или на банковский бизнес с возможностями зарабатывания огромных денег и формирования золотовалютных и прочих резервных фондов. В данной статье мы лишь очень коротко упоминаем о роли государства в понимании значения и необходимости развития страхования. Эта роль государства, в свою очередь, оказывает влияние на предпочтения населения по видам сбережений и на преимущества заключения договора страхования. С одной стороны, государство формирует мнение определенной доли населения. С другой стороны, именно государство своими целями, задачами и решениями определяет уровень благосостояния населения, влияние которого на страховой рынок мы рассматриваем в данной статье. Сама проблема роли государства в развитии страхования является очень глубокой и емкой и исследуется отдельно.

Важнейшей проблемой развития страхования, которая находится в непосредственной близости и взаимосвязи с вопросом влияния благосостояния населения на развитие страхового рынка является проблема неразвитости страховой культуры населения. Данной теме посвящено достаточно много научных работ [3; 6; 13-15]. Страховая культура в части понимания сущности страхования и владения информацией о страховых продуктах, имеет огромное значение даже при наличии свободных денежных средств - надо не просто иметь свободные денежные ресурсы, надо знать, что их можно эффективно использовать через механизм страхования (как передача риска или способ сбережения).

В подтверждение суждений о зависимости страхования от доходов населения приведем результаты опроса «Ваши предпочтения в страховании», проведенного среди жителей республики Марий Эл, в котором участвовало 348 человек из различных возрастных групп и с разным уровнем дохода, выявили «факторы, обуславливающие отказ потенциальных страхователей от страховых продуктов, и причины их недоверия страховым компаниям». Во-первых, данный опрос показал, что только 41 \% из опрошенных пользуются услугами страхования [3]. Предполагаем, что часть их них имела ввиду обязательное страхование автогражданской ответственности владельцев транспортных средств, а у части - заключение договора страхования связано с получением кредитов. Во-вторых, опрос показал, что «основной причиной отказа от приобретения еще одного или первого страхового полиса явились «отсутствие свободных средств» - так ответили 45,2 \% опрошенных» [3].

Таким образом, исследование благосостояния населения как фактора развития страхования остается актуальным. В более глубоких форматах данные исследования представляют картину возможностей развития страхования в целом, выявляет болевые точки и определяет пути взаимодействия страховщиков с государством по пути развития страхования, а на уровне самих страховых компаний влияет на разработку стратегий развития компаний, выбор приоритетных сегментов, разработку правил страхования и формирование продуктовых линеек.

\section{Список использованной литературы}

1. Худяков А. И. Теория страхования / А. И. Худяков. - М. : Статут, 2010. - 656 с.

2. Григоренко И. В. Анализ потенциала развития рынка страхования жизни населения: финансовый аспект / И. В. Григоренко, Е. А. Шкарупа // Фундаментальные исследования. - 2016. - № 3. - С. 14-19.

3. Закирова О. В. Низкая страховая культура как основной фактор неразвитости страхового рынка / О. В. Закирова, О. В. Соловьева // Взаимодействие государства и страховых

\section{Baikal Research Journal}

электронный научный журнал Байкальского государственного университета 
организаций: проблемы и перспективы развития : материалы Междунар. страхового форума. Пермь, 8-9 июня 2011 г.) / гл. ред. И. Ю. Макарихин; отв. ред. М. Ю. Молчанова. Пермь : Перм. гос. ун-т, 2011. - С. 39-46.

4. Что изменилось в доходах, расходах и потреблении российского населения / Л. Н. Овчарова, С. С. Бирюкова, С. А. Тер-Акопов, Е. Г. Варданян. - М. : НИУ ВШЭ, 2014. - 42 с.

5. Белехова Г. В. Социально-демографические особенности финансового поведения населения / Г. В. Белехова // Проблемы развития территории. - 2015. — № 1. - С. 100-115.

6. Зубец А. Н. Страховой маркетинг / А. Н. Зубец. - М. : Анкил, 1998. - 255 с.

7. Степанова С. М. Анализ и основные тенденции развития рынка финансовых услуг как структурного элемента потребительского рынка: региональный аспект / С. М. Степанова, Я. Э. ЗЖукова, Л. И. Шинкаренко // Современные наукоемкие технологии. Региональное приложение. - 2016. - № 2. - С. 70-80.

8. Хитрова Е. М. Формирование цены на рынке страховых услуг / Е. М. Хитрова // Страховое дело. - 2014. - № 3. - С. 3-7.

9. Андреева Е. В. Страхование жизни: социально-экономическое значение и направления развития / Е. В. Андреева, О. И. Русакова, Е. М. Хитрова. - Иркутск : Изд-во БГУЭП, 2013. - 160 с.

10. Русецкая Э. А. Рынок банкострахования в РФ: реалии и перспективы развития / Э. А. Русецкая // Страховое дело. - 2015. - № 4. - С. 21-27.

11. Гребенщиков Э. С. Масштабы и риски незастрахованности / Э. С. Гребенщиков // Финансы. - 2014. - № 12. - С. 56-60.

12. Ермоленко Г. Г. Современное состояние и перспективы развития страхового рынка Российской Федерации / Г. Г. Ермоленко // Научный вестник: Финансы, банки, инвестиции. - 2014. - № 4. - С. 51-60.

13. Ахвледиани Ю. Т. Стратегические направления развития российского страхового рынка / Ю. Т. Ахвледиани // Страховое дело. - 2015. - № 12. - С. 3-8.

14. Страхование : учебник / под ред. Т. А. Федоровой. - 3-е изд., перераб. и доп. М. : Магистр, 2008. - 1006 с.

15. Русецкая Э. А. Страховой рынок России: проблемы и перспективные направления развития / Э. А. Русецкая. - Ставрополь : Тэсэра, 2013. - 115 с.

\section{References}

1. Khudyakov A. I. Teoriya strakhovaniya [Theory of Insurance]. Moscow, Statut Publ., 2010. $656 \mathrm{p}$.

2. Grigorenko I. V., Shkarupa E. A. Analysis of development potential for personal life insurance market: financial aspect. Fundamental'nye issledovaniya = Fundamental Investigations, 2016, no. 3, pp. 14-19. (In Russian).

3. Zakirova O. V., Solovyova O. V. Low insurance culture as a main factor of insurance market underdevelopment. In Makarikhin I. Yu., Molchanov M. Yu. (eds). Vzaimodeistvie gosudarstva $i$ strakhovykh organizatsii: problemy $i$ perspektivy razvitiya. Materialy Mezhdunarodnogo strakhovogo foruma. Perm', 8-9 iyunya $2011 \mathrm{~g}$ [Interaction of government and insurance organizations: problems and prospects of development. Perm, June 8-9, 2011]. Perm State University Publ., 2011, pp. 39-46. (In Russian).

4. Ovcharova L. N., Biryukova S. S., Ter-Akopov S. A., Vardanyan E. G. Chto izmenilos' $v$ dokhodakh, raskhodakh i potreblenii rossiiskogo naseleniya [What has changed in incomes, expenses and consumption of Russian population]. Moscow, Higher School of Economics Publ., 2014. $42 \mathrm{p}$.

5. Belekhova G. V. Socio-demographic peculiarities of population's financial behavior. Problemy razvitiya territorii $=$ Problems of Territorial Development, 2015, no. 1, pp. 100-115. (In Russian).

6. Zubets A. N. Strakhovoy marketing [Insurance Marketing]. Moscow, ANKIL Publ., 1998. $255 \mathrm{p}$.

7. Stepanova S. M., Zhukova L. I., Zhukova Yu. E., Shinkarenko L. I. Analysis and main trends of development of financial service market as a structural element of consumer market: a regional aspect. Sovremennye naukoemkie tekhnologii. Regionalnoe prilozhenie $=$ Modern High Technologies. Regional Application, 2016, no. 2, pp. 70-80. (In Russian).

\section{Baikal Research Journal}


8. Khitrova E. M. Pricing for insurance market. Strakhovoe delo = Insurance, 2014, no. 3, pp. 3-7. (In Russian).

9. Andreyeva E. V., Rusakova O. I., Khitrova Ye. M. Strakhovanie zhizni: sotsialno-ekonomicheskoe znachenie $i$ napravleniya razvitiya [Life Insurance: Socio-Economic Significance and Development Directions]. Irkutsk, Baikal State University of Economics and Law Publ., 2013. $160 \mathrm{p}$.

10. Rusetskaya E. A. Banking insurance market in Russia: realities and prospects. Strakhovoe delo $=$ Insurance, 2015, no. 4, pp. 21-27. (In Russian).

11. Grebenshchikov E. S. Scope and risks of underinsurance. Finansy = Finance, 2014, no. 12, pp. 56-60. (In Russian).

12. Ermolenko G. G. Current state and prospects of development of the Russian Federation. Nauchnyi vestnik: Finansy, banki, investitsii = Scientific Bulletin: Finance, Banking, Investments, 2014, no. 4, pp. 51-60. (In Russian).

13. Akhvlediany Yu. T. Strategic directions of developing Russia's insurance market. Strakhovoe delo = Insurance, 2015, no. 12, pp. 3-8.

14. Fedorova T. A. (ed.). Strakhovanie [Insurance]. 3rd ed. Moscow, Magistr Publ., 2008. $1006 \mathrm{p}$.

15. Rusetskaya E. A. Strakhovoi rynok Rossii: problemy i perspektivnye napravleniya raz vitiya [Russia's insurance market: problems and promising development directions]. Stavropol, Tesera Publ., 2013. 115 p.

\section{Информация об авторе}

Кузнецова Надежда Васильевна - кандидат экономических наук, доцент кафедры страхования и управления рисками, Байкальский государственный университет, 664003, г. Иркутск, ул. Ленина, 11, e-mail: nadezhda1978@mail.ru.

\section{Author}

Nadezhda V. Kuznetsova - PhD in Economics, Associate Professor, Chair of Insurance and Risk Management, Baikal State University, 11 Lenin St., 664003, Irkutsk, Russian Federation; e-mail: nadezhda1978@mail.ru.

\section{Библиографическое описание статьи}

Кузнецова Н. В. Благосостояние населения как фактор развития страхового рынка / Н. В. Кузнецова // Baikal Research Journal. — 2016. — T. 7, № 6. — DOI: 10.17150/24116262.2016.7(6).3.

\section{Reference to article}

Kuznetsova N. V. Human welfare as a factor of insurance market development. Baikal Research Journal, 2016, vol. 7, no. 6. DOI: 10.17150/2411-6262.2016.7(6).3. (In Russian).

\section{Baikal Research Journal}

